\title{
The Experiences of Older Persons and Their Adult Children on Maintaining Positive Parent-child Relationships
}

\author{
Marcelle Dianne Boshoff, Nevashnee Perumal*
}

Department of Social Development Professions, Nelson Mandela University, South Africa

\begin{abstract}
The incidence of increased life span as well as a lack of care for older persons, gave rise to the South African Older persons Act (Act No 13 of 2006), which provides a clear indication of the expectations of caring for older persons within communities and families. With many older persons relying on the relationships they have with their children in their golden years, to be fulfilling and loving, this study aimed to explore the experiences of older persons and their adult children from a strengths based perspective by focusing on how they maintain positive relationships. This study adopted a qualitative research approach which was exploratory and contextual in nature, applying a narrative strategy of inquiry. Empirical data was collected from two sample sets, using a non-probability purposive sampling method: i) five older persons who were retirees of an automotive company in South Africa and ii) at least one of their adult children. Individual, semi-structured face to face interviews were conducted with both sample sets. Thematic data analysis technique was used to analyse the data collected. This article reports on two themes generated from the findings of the study.
\end{abstract}

Keywords Adult Child, Care, Elderly, Experiences, Retiree

\section{Introduction}

The parent-child relationship is acknowledged by many researchers as one of the most significant relationships experienced in one's life (Birditt, Miller, Fingerman \& Lefkowitz, 2009; Kuehnle \& Ellis, 2002). However, as parents age and their children reach adulthood many of these relationships undergo changes and are placed under tremendous strain as the needs of elderly parents and adult children differ. Recent studies, such as that conducted by Newby (2010) as well as practice observations revealed that adult children feel less obligated to care for their elderly parents as was the case in the past. It is increasingly evident that adult children currently often take care of their elderly parents out of guilt and obligation as opposed to love and compassion (Newby, 2010). Kinsella (2005:27) points out that there is much debate regarding family bonds and whether these bonds have strengthened or disintegrated over time and Newby's (2010) suggestion indicates that the quality of bonds appear to be increasingly eroded. This leaves the elderly person feeling very lonely and neglected if the assistance by adult children is purely out of obligation.

\section{Background to the Study and Literature Review}

Historically, families have been the environment where elderly were known to thrive and were cared for (Bookman, 2011). It is fundamentally through the family that each generation is replaced by the next; that children are born, socialized and cared for until they attain their independence; and that each generation fulfills its care responsibilities to minors, older persons, and the sick (White Paper on Families in South Africa, 2012).

Over the years, many changes have taken place within the family structure, specifically since 1900's up to the twentieth century. Many cultures have certain expectations regarding the care of the elderly in society; some are more formal than others. Many elderly are of the opinion that their children should be taking care of them unconditionally as they have done for their children. However children may be of the opinion that their elderly parents should have made provisions for their later years and that the government should also be part of the caring process. In contrast to this notion, the South African Older Persons Act (Act No 13 of 2006) places emphasis on keeping the elderly within communities and having community based care facilities. This legislation attempts to reduce the burden that 
institutionalization of elderly has on governments. Children are encouraged to take care of their elderly parents instead of institutionalizing them as a first option.

The South African government, in its present, young stage of democracy is struggling to provide its people with basics, such as housing and employment therefore limiting the extent of support they are able to offer the elderly and clearly not prioritizing this sector of the community (Powell, 2013). Many sources indicate that in a changing society, it is vital that there are more stakeholders involved in caring for the elderly population (Bookman, 2011), and if they all worked together then it would alleviate much of the pressure that the elderly experience with regards to their care.

From practice observations when many people are asked what they expect life to be like when they are elderly, many answer that they would like being surrounded with family, friends, children and their loved ones. Few people will admit that they regret or never wanted to have children. Even fewer of these parents will openly express that their children were mistakes to have. Many elderly question whether they would still have had children knowing how they would be treated by their children when they most need their children. Abeles et al. (1994:1), recognize that not all elderly are frail, physically dependent and requiring financial assistance from their children. Studies conducted by Ramshala (2000) on aging in more recent years focused more on healthy elderly who reside in communities as opposed to the frail and needy elderly, indicating that care for the elderly need not be stereotyped as the elderly being "in need". The study indicated that instead of viewing older people as senile and fragile, they should be viewed as persons with strengths and interdependence. The elderly tend to thrive on the support and caring from their adult children, which increases their life satisfaction (Lowenstein, Katz \& Gur-Yaish, 2007).

Very few elderly are prepared for the reality of loneliness that they are faced with. Growing old has become associated with loneliness and isolation (Rosenberg-Jarvos, 2006:1). As a culture, humanity has become uncomfortable with dependency and it is associated with weakness. According to Rosenberg-Jarvos (2006), the society people live in today, does not respect and value the aging population. Attention is not given to the stories that elderly have to tell or valuable contributions that they still can make. However, according to Frankl (1997), children give people meaning in their lives. If people have something meaningful in their lives, they will live longer (Fankl, 1992). By implication, relationship with adult children is most meaningful for the elderly offering them longevity although it is often not socially acceptable for the elderly to be dependent on their adult children. The concern of an aging population is of a global nature. According to the World Health Organization's report on Global Health and Aging (2011), developed countries will face a projected increase of 71 percent in the number of older people whereas developing countries will face a projected increase of 250 percent over the next 35 years (WHO, 2011). Not only are populations growing older, but the older populations are also aging which contributes to the "oldest old" which according to Kinsella (2005:7) are people who reach the age of 80 or even older.

Soon the world will have more elderly people than young children for the first time in recorded history, according to the World Health Organization (2011). History has shown that children have always outnumbered the elderly population and that the elderly are always significantly less than the young (National Institute on Ageing, 2011). The prediction is that the population will continue growing old and the trend of the aging population will even accelerate (Kinsella, 2005:6). This increase in older populations will create tremendous pressure on society and the growing question of who will endure the burden of those who are aging well beyond their years.

\section{Problem Formulation}

The elderly population might become a burden on governments in the near future as many people have not planned adequately for their retirement and thereafter (Bookman 2011, Gelineau 2013, Kinsella 2005, Ramshala 2000, WHO 2011). The Older Persons Act No 13 of 2006 supports community and family based care for the aged (RSA, 2006). However literature as well as practice observations indicate that large numbers of adult children are not committed to caring for their parent(s) and/or do not have good relationships with their elderly parents (Swain 2011, Wurtzel 2014).

There seems to be very little research into those elderly parents who do have caring relationships with their adult children (O'Connor, 1994:53). Due to the nature of aging in the future and the demand that the elderly will be placing on formal systems for care, there will be many more elderly that will have to rely on their adult children to meet their needs (Ferring, Michels \& Boll, 2009). This often leads to many frustrations within the elderly parent - adult child relationship and; since limited knowledge exists on the experiences of elderly parents and their adult children on maintaining mutually caring and satisfying parent-child relationships, this further limits social work services to the elderly. Based on the aforegoing, this study sought to explore and describe the mutually caring and satisfying relationships that elderly parents share with their adult children.

\section{Theoretical Frameworks}

Family Development Theory according to Duvall (1962), as well as Ecological Systems Theory (Bronfenbrenner, 1994) underpinned this study

\section{Family Development Theory}

Henry Plunkett and Sands (2011) explain the Family Development Theory as a useful mechanism to describe patterned change, the dynamic nature of families and how 
change occurs in the family life cycle. The major contributors to this theory which originated during the 1940's and 1950's were Paul Glick, Evelyn Duvall and Reuben Hill (Henry et al., 2011). These theorists have used the Family Developmental Theory to explain processes observed in families over time. Major constructs of Family Development Theory are explained in a life cycle. The family life cycle divides the family experiences into stages over the life span and describes changes in family structure and roles during each stage which is quite significant to this study based on the elderly parents' life stage and the adult children's life stage The Family Life Cycle consist of 8 stages according to Erikson (1983) namely:

Stage 1 which refers to married couples (without children). During this stage of family development the individuals will have established a mutually satisfying marriage and adjusting to roles of husband/wife. This stage also allows the couple to get used to being pregnant and fitting into each other's family systems.

Stage 2 is the childbearing family stage (children aged between birth and 30 months). Additional roles are added for the couple like mother and father. The couple modifies their lifestyles to accommodate an infant and work toward establishing a satisfying home for the parents and infant.

Stage 3 is the families with pre-school children stage (children aged between $21 / 2$ - 6 years). Parents adapt to needs of their pre-school children and cope with depletion of energy and lack of privacy. Children in this stage deal with adapting to brothers or sisters as well as being a daughter or son to their parents.

Stage 4 is the families with school-going children (children aged between 6-13 years). This stage is vital for encouraging educational achievements and fitting into the community that the family resides in. More roles are added to each individual in the family like scholar and friend.

Stage 5 refers to the families with teenagers' stage (children aged between 13-20 years). Parents attempt to establish post parental interest and teens balance freedom with responsibility.

Stage 6 is the families as launching centers stage (first child has left home - last child preparing to leave). The family launches the youth into young adulthood and maintains a supportive home base for them.

Stage 7 is the middle age parents' stage (empty nest to retirement). This is when the couple re focus on their marriage relationship and maintain ties with older and younger generations. They adjust to being grandparents.

Finally stage 8 refers to the elderly family members stage (retirement to death of both parents). This stage brings about many challenges of its own. Couples may be separated by death and they may become widows and/or widowers. The family copes with death and living alone, selling of possessions due to age and adjusting to retirement.

This theory also speaks about the Developmental Tasks which are the growth responsibilities that arise at certain stages in the life of the family. Even though each human being is different and not all follow the same patterns, there is still a common pattern in life that is experienced by many couples and families. This is what Family Development Theory depicts.

Elderly parents as well as adult children may fall into any of the stages depending on their current life circumstances, making all 8 stages applicable to this study.

\section{Bronfenbrenner's Ecological Systems Theory}

According to Bronfenbrenner (1994), various systems in the life of older persons and their adult children interact with one another and impact one another, whether they are directly involved with that system. The different systems being the Micro-systems which are the immediate environments that people engage with, the Meso-systems which is when two or more systems are linked, Exo-systems which are the larger social systems, Macro-systems are those that extend over the micro and meso and the Chrono-systems are those dimensions that relate to the child over time.

The micro-systems are the immediate environments that developing humans engage with such as families, school, work and peers. These interrelations in the family will help children build trust and mutuality with their significant people (Bronfenbrenner, 1994:39). Therefore while the adult child is engaged in their microsystem (husband/wife and/or children) at home they need to at the same time engage with elderly parents who feature in the exo-system.

The meso-system is the interaction and linkages between two or more settings of the developing person from their micro-systems; this is the interaction of school and home or the workplace.

Exo-system is the larger social system in which the child may not directly function. These systems still impact on the child's development by interacting with microsystems of the child. So a parent's workplace or a very demanding elderly parent may place extra pressure on the adult child and even though the family of the adult child are not directly in contact with the elderly parent they all still feel these pressures.

The macro-system is the overarching of the micro and meso-systems. The macro-system is the belief systems, knowledge, customs and even lifestyles that affect the conditions and processes of the microsystems.

Chrono-system refers to the dimension of time as it relates to a child's life.

Adult children are in various stages of family development as they are interacting with various systems simultaneously in their lives. The demands of adult children versus elderly parents' needs play major roles in the aging parent - adult child relationships.

Family Development theory and Ecological systems theory were therefore found to be most relevant to this study area. 


\section{Research Design}

\section{Research Approach and Design}

This study utilized the qualitative research approach wherein the researcher set out to explore, understand, analyse, describe and interpret the findings based on undertaking face to face semi structured interviews which were guided by themes (Rossmann \& Rallis, 2012:9). From the foregoing, it is evident that this study followed an exploratory descriptive, contextual research design. The purpose of the exploratory research design is to gain insight into a particular topic of interest (De Vos, 2005). In addition, narratives of elderly parents and their adult children who have experienced the phenomenon of mutually caring and satisfying relationships will be used as the strategy of inquiry for the study (Bloomberg \& Volp, 2012).

\section{Research Goal and Objectives}

The research goal was to enhance the understanding of mutually caring and satisfying elderly parent - adult child relationships.

The objectives of this study were to: explore and describe the experiences of elderly parents who have positive relationships with their adult children; explore and describe the experiences of adult children who have positive relationships with elderly parents; make recommendations based on the findings of the study to professionals in the field of social work to enhance the relationships between elderly parents and their adult children of their clients.

The central research question for this study was:

What are the experiences of elderly parents and their adult children of maintaining mutually positive parent-child relationships?

\section{Sample}

The population for this research study was all retirees of an automotive manufacturing company in South Africa which consists of approximately 1800 retirees. Due to the large number of elderly that this company represented within communities the company was used as an entry point to the sampling group.

A non-probability purposive sampling technique was used to select the sample based o on the following criteria:

- $\quad$ Retirees of an automotive manufacturing company over the age of 55 who have one or more living children.

- $\quad$ Retiree must perceive their relationships with their adult children to be mutually satisfying

- Adult children of the retirees must be over the age of 25 years

- $\quad$ Adult children must not be residing with the elderly parents.
- $\quad$ Adult children must perceive their relationship with their elderly parents to be mutually satisfying.

The researcher collected data from 5 families with elderly parents and adult children. Although this is considered a small sample, the focus of the study was not to generalize the findings but rather to understand the experiences shared by the participants.

\section{Data Collection}

Face to face semi-structured in-depth interviews were conducted separately with both elderly parents and their adult children to allow for the story of their relationship to unfold. A pilot study, which guides the researcher to further refine interview questions and procedures for the research (Creswell 2013:165), was conducted with one retiree and their adult child.

\section{Entry into the Research Site}

Permission was obtained from the Human Resources Department of the automotive manufacturing company to use their database of retirees. Ethics approval to conduct this study was obtained from the Ethics Committee of the Health Sciences Department at Nelson Mandela Metropolitan University.

\section{Findings and Discussion}

\section{Biographical Data}

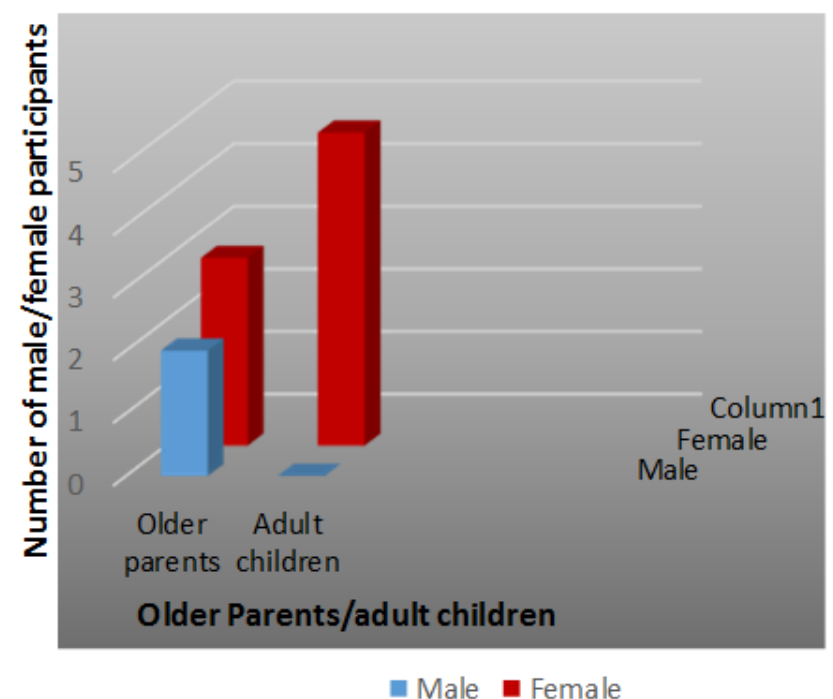

Chart 6.1. Gender of participants

The gender of older persons varied between male and female. The total number of participants in the study was 10 . There were two (2) male older persons who volunteered to participate and there were three (3) female older 
participants who volunteered to take part in the research study. There were no male adult children who took part in the study and all five (5) adult children participants were female. The total number of male participants in the study was two (2) and total number of female participants was eight (8).

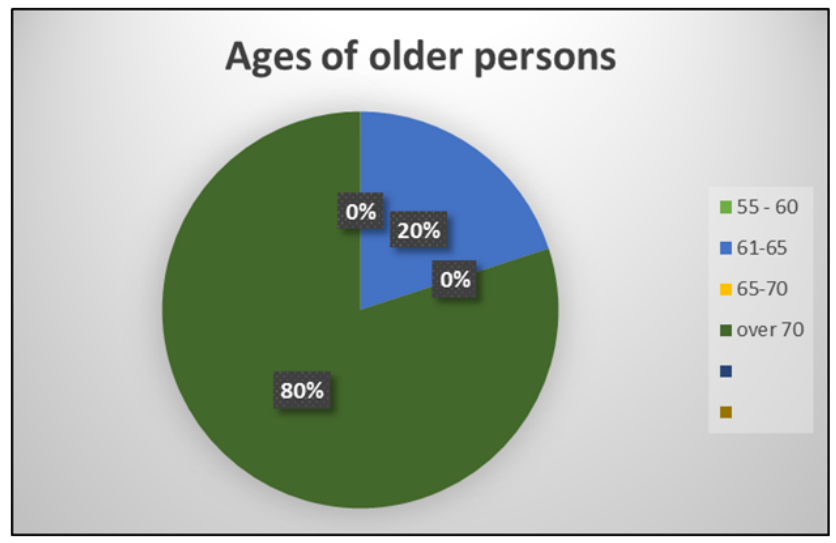

Chart 6.2. Ages of older parent participants

In this study eighty percent $(80 \%)$ of older persons were above the age of seventy (70) which was a total of four (4) older parent participants. The remaining twenty percent $(20 \%)$ of the older parent participants were between the ages of sixty one (61) and sixty five (65) totaling one (1) older parent participants. There were no older parent participants between the ages of 55-60 or 65-70.

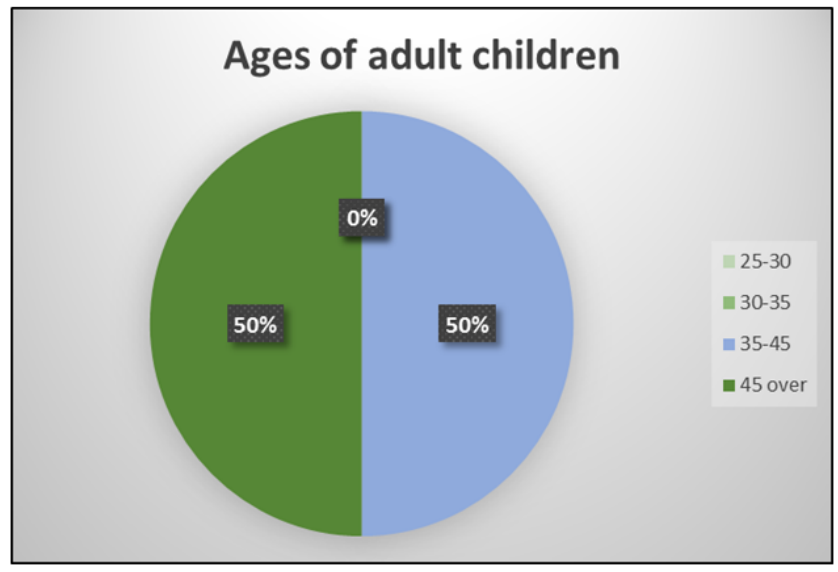

Chart 6.3. Ages of adult children participants

The ages of the adult children were divided into two different categories. The one group was between the ages of thirty five (35) and forty five (45) whilst the other group was over the age of forty five (45). There were no adult children between the ages of 30-35.

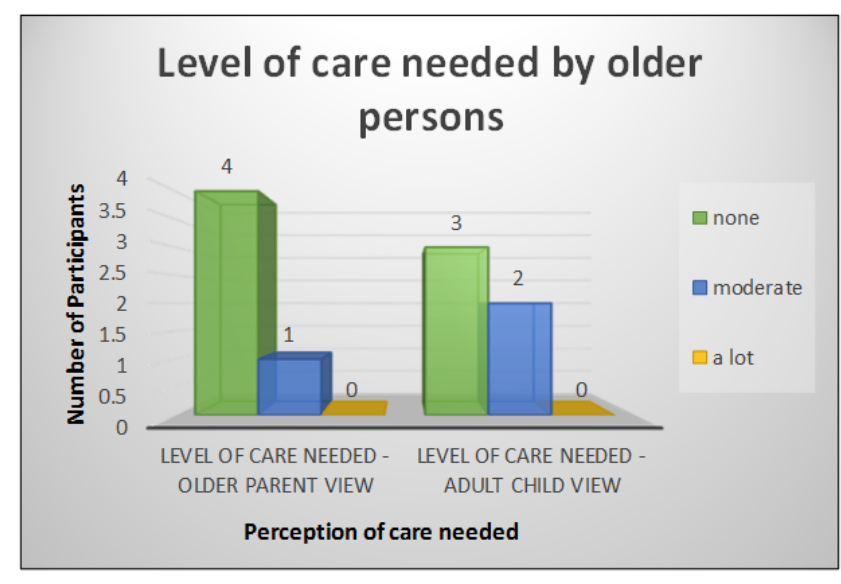

Chart 6.4. The level of care needed by older persons in their view and their adult child's view

Above is the reflection of the level of care that is needed by older persons according to older persons and the adult children. The view of older persons and adult children are very much in agreement with one another. Four (4) out of five (5) older persons felt that no care was needed as opposed to three (3) of the five (5) adult children who felt that no care was needed by the older person. One (1) older parent and two (2) adult children agreed that moderate care was needed by the older parent. None of older persons or adult child felt that the older person needed a lot of care.

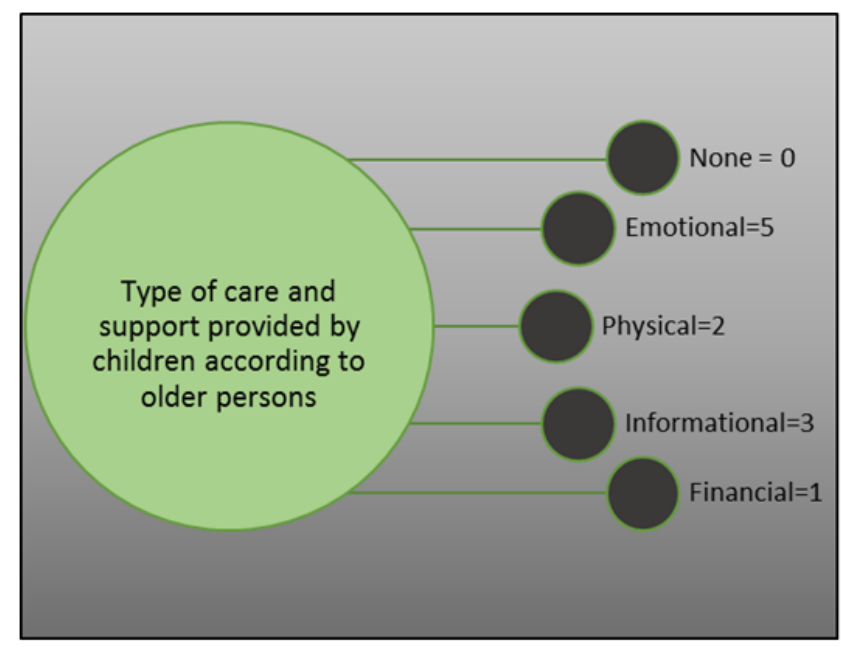

Figure 6.7. Care and support provided by adult children according to older persons

Older persons were asked to indicate what type of care or support they receive from their adult children. All of older persons indicated that they received some sort of support or care from their adult children. The support that was indicated the most was emotional support from their adult children with all five (5) older persons feeling that their adult children provide them with emotional support. Two (2) of the five (5) older persons indicated that they receive physical assistance from their adult children. Informational 
support ranked second highest on support provided with three (3) older persons receiving informational support from their adult children. Only one (1) of the five (5) older persons said that they receive financial support from their adult child.

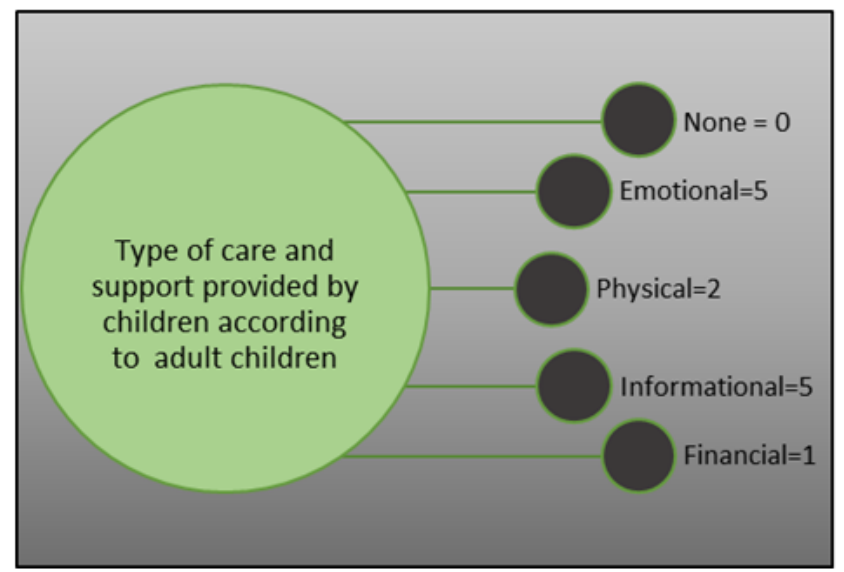

Figure 6.8. Views of adult children on the type of support and care provided to older persons

Adult children gave a very similar depiction of care and support they provide to the older person. All adult children reflected that there is some kind of support provided to the older person. Here again, it is evident that all five (5) adult children felt that they provide emotional support to the older person. Two (2) adult children indicated that they provide some physical care for the older person. Informational support ranked second highest, with five (5) adult children indicating that they provide this type of support to the older person. Only (1) adult child provides financial support to her elderly parent.

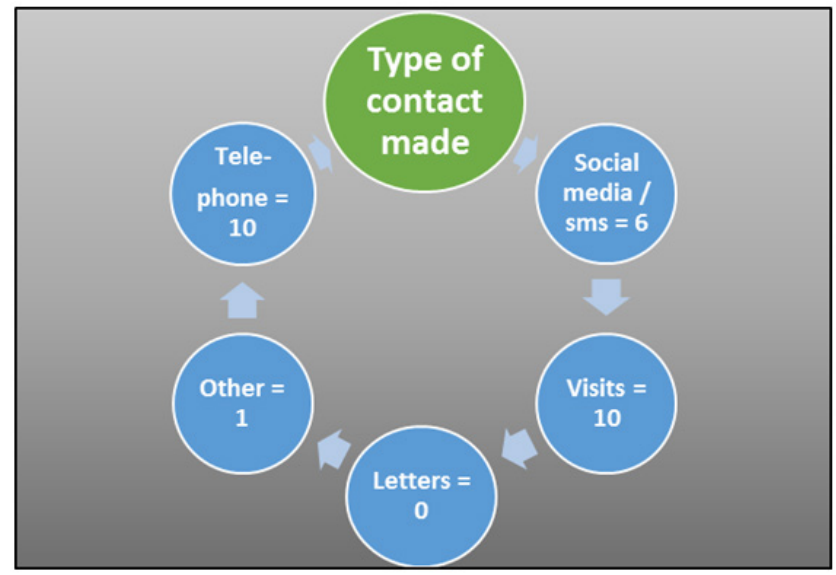

Figure 6.9. Types of contact that is made between older persons and their adult children
All ten (10) participants indicated that they have telephonic contact with each other. Six (6) participants indicated that they use social media or text messaging to keep in contact with one another. All ten (10) participants reflected that they visit each other as part of staying in contact. None of the participants used letters to connect. One (1) participant said that they will send messages to each other via community members if they need to.

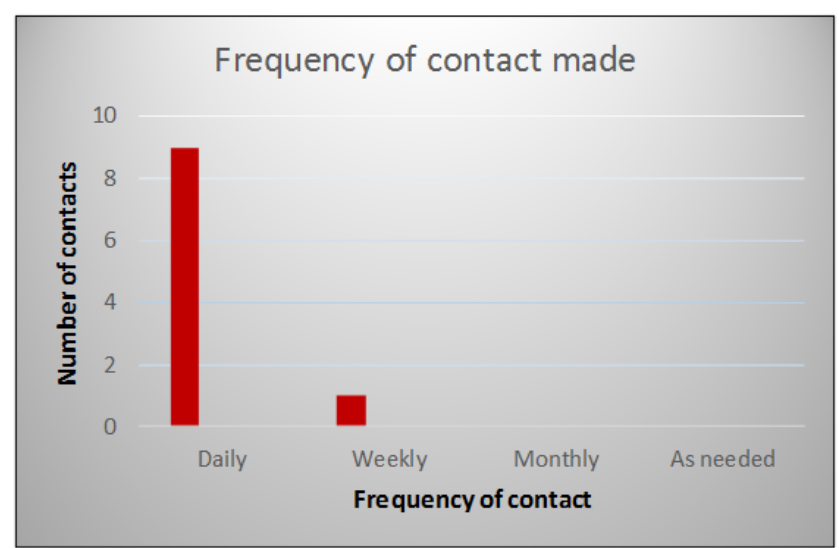

Chart 6.5. The frequency of contact made between older persons and their adult children

Nine (9) participants said that they have daily interaction and contact with each other via some of the methods indicated in Chart 6.5. While only one (1) participant who lives in a different city to her elderly parent indicated that they have weekly contact with each other.

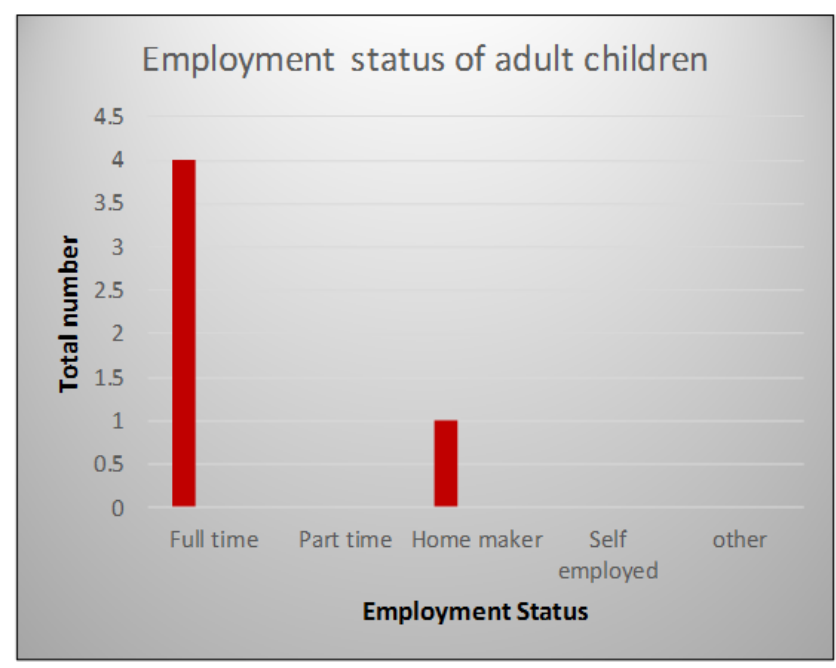

Chart 6.6. Employment status of adult children in the study

Four (4) of the five (5) adult children are employed full time and only one (1) of the adult children indicated being a home-maker who does not participate in the formal employment sector, but instead takes care of the home. 


\section{Research Findings: Themes and Subthemes}

Although this study generated the following themes, only the first two themes will be discussed in this paper.

Theme 1: The experiences of older persons and adult children of the parent-child relationship

Subtheme 1: $\quad$ Experience of older persons of their relationship with their adult child

Subtheme 2: $\quad$ Experience of adult children of their relationship with their elderly parent

Theme 2: $\quad$ Significant contributors to the positive older persons' parent-adult child relationship

Subtheme 1: $\quad$ Parental non-dominance

Subtheme 2: The lifespan of the parent-child relationship

Subtheme 3: Mutual participation and interaction by all generations within the family

Subtheme 4: Communication

Subtheme 5: $\quad$ Respect

Theme 3: $\quad$ Family solidarity

Theme 4: $\quad$ Experiences of Challenges in the older parent - adult child relationship

\section{A brief introduction to each parent-child relationship}

A - C This refers to the participants in the study whose names will not be disclosed for confidentiality reasons as per the discussions of findings below.

\section{Kind-hearted Long Distance Father Daughter Duo}

Her father was the traditional head of the household and the breadwinner in their home. Although having many siblings, the adult child never felt that they were competing for the attention of her father. Her father always dealt with them in a soft and kind manner. Even though they do not live in the same city, they ensure that this does not impact negatively on their relationship.

\section{Enthusiastic Mother-daughter Relationship}

The mother is quite a strict and rigid lady, even with those in her community. She is seen as the person who everyone can go to and know they will be helped. The daughter admires this characteristic of her mother the most. There is nothing that her mother cannot accomplish, even when it came to raising 10 children after her husband passed away. The mother holds her daughter in high esteem for who she has become and they have a very special interdependent mother-daughter relationship. Even though they have had their fair share of challenges in the relationship, they continue to hold on to the foundation which was built on love and respect.

\section{Traditional Mother-daughter Kinship}

The daughter has taken on a very caring and nurturing role with her mother who is in her golden years. She loves attending to her needs and even though the needs seem to be increasing over the years, they share an understanding and mutual respect for each other's boundaries and abilities.

\section{Wise, Thoughtful and Well Informed Father-daughter}

Mr. A is so in tune with his relationship that he experiences with his daughter that nothing seems like it can break or disturb the strong bond that they share. They speak so highly of each other and the opinions that they hold. They have a deep connection and appreciation for each other. When they speak or interact, it is with the other person's best interests at heart.

\section{Modern Involved Mother-daughter Team}

Having been a very young mother, she is now able to reap the benefits of this by being involved in the lives of her daughter and granddaughter. She is able to do things that may not have been possible had she been somewhat older. She plays and laughs with, as well as mentors her daughter and granddaughter. She reflects the person who they would like to become. They may not always agree on how things should be done, but they always come back to what is important which is being there for each other.

\section{Theme 1: The Experiences of Older Persons and Adult Children of the Parent-child Relationship}

\section{Subtheme 1: Experience of Older Persons of their Relationship with their Adult Child}

When each participant was asked to describe how they experienced the relationship with their adult child, they seemed to be in agreement that their relationships were all very positive. This was indicated by the following statements made by different older parent participants: 
- "I have such a good relationship with her."

- $\quad$ "She and I have a relationship that differs from the other children. The relationship between me and $B$ is very good."

- "Firstly I have a very good relationship with my child."

These responses by the elderly parent participants were very clear in that they professed to have good relationships with their adult children. The participants also described their relationships as having mutual reciprocity. When we refer to literature with regards to the impact of mutual reciprocity in the elderly parent-adult child relationship, it has some noteworthy influence on the perception of the satisfaction in the relationship.

Lowenstein et al. (2007) found that parents who felt emotionally close to their children were happier and more satisfied with their relationship. This mutual reciprocity is indicated by older persons in the following statements:

- "When there is anything that makes her unhappy she will come to me for advice: 'Dad what do you think of this?",

- "When I have a problem in the house I go to her and ask her $C$ what now?

- "We give each other advice."

These reactions of participants indicated a positive aspect of the relationship. The feeling was that when they or their adult child were in need of informal support from one another, each other were available. Lowenstein et al. (2007) confirm that providing informal support to others appears to exert a positive effect on well-being in later life.

The Global Age Watch (2013) discovered that the capacity of older persons to participate in their communities was a key determinant in their well-being in later years. This was reiterated in the interviews with older persons where they felt that their interaction with their communities was vital and impacted on their relationships with their adult children. From an ecological systems perspective, when older persons interact with other systems such as their adult children and neighbours, they will improve their functioning and in turn their relationships with adult children and the community also seem to benefit from these interactions instead of older persons functioning in isolation from these systems. Organisations such as retirement villages and churches are found in the micro, meso and exo-systems of an individual (Bronfenbrenner, 1994). Some of older persons even included their adult children in their community activities:

- $\quad$ "We visit people in the community who have deaths. Yesterday I asked her when we are going to the woman who had two deaths?"

- $\quad$ "The younger one is a fabulous musician and I have him come here and sing to the residents."

\section{Subtheme 2: Experience of Adult Children of their Relationship with Older Persons Parent}

This is indicated below when the adult children describe their views on the relationship with older persons:

- "I would say that we have always had a good relationship, specifically with him I think."

- "I have a good relationship with both my mom and my dad."

- "Oh, my mother and I have a very good relationship."

Mutual reciprocity also plays a big role in the experience of the adult child and their relationship with the older person. One adult child describes her mother being at her side when she was going through a very difficult time in her adult life. When the adult child experienced an unsettling experience, the older parent provided support, thereby enabling homeostasis to be attained. This fits in with the ecological theory as espoused by Bronfenbrenner (1994) Even though her mother says that her daughter assists her when she can, the daughter indicates this exact behavior from her mother when she needed her:

- "She said that she would help and I do not have to do this by myself, she helped me."

Another adult child confirms the above sentiment with her relationship with her father, agreeing that her elderly parent reciprocated support with her family. This adult child found herself in the childrearing stage of family development (Duvall, 1962) and had to rely on her parent in order to assist with some of the responsibilities with her children. The older person found himself having more time available after withdrawing from the labour market (a very significant system that was present in the life of the older person for the most of his life) freeing him up to be able to invest this time into his grandchildren and indirectly support his adult child:

- "I think what has helped is my own children, they would go there in the afternoon after school and they would look after them when they retired."

\section{Theme 2: Significant Contributors to the Positive Older Person's Parent-adult Child Relationship}

\section{Subtheme 1: Parental Non-dominance}

Erikson's Life Span Development Theory (1959) consists of eight stages from birth to death. In stage five, Erikson discusses young adulthood. At this stage, young adults need to form meaningful relationships with people outside of their immediate family or parents (Erikson, 1983). When parents are not able to establish this new level of relationship with their adult children, they experience some major challenges within the parent-child relationship. The parent-child relationship in later life is very challenging because it is constantly changing. For parents to accommodate the change according to Pickhardt (2010) 
they need to do the following: a) be more tolerant b) adjust to role reversal and c) demotion.

An older parent confirms this statement above by acknowledging that:

- "Children turn away from parents because they have changed their lifestyles that are not approved, parents then need to keep on loving."

- "We must adjust to our children and their way of life."

Pickhardt (2010) clarifies that parents will inevitably become less significant as parents realize that their children have established themselves in the world and are preoccupied with managing a separate life from the older person, by finding a partner and having a family of their own. Pickhardt (2010) continues to explain that this involvement may be less, but it does not mean that the caring is less, while allowing the adult child the opportunity to discover how to manage all these processes without constant pressure but rather support and assistance. The parental role does not end when the adult child reaches this phase, but yet again changes and evolves into cheerleader, captivated audience and emotional supporter. When parents understand the change in roles, the need that adult children have for their parents will never disappear.

This information shared by Pickhardt (2010) was reiterated by both parents and their adult children in the study. Adult children felt that sometimes they are not available, but the older person seems to offer the relationship as a safe place for their adult children to feel comfortable. Duvall (1962) continues to say that even though a child leaves their parents' home and moves on to make a place of their own their parents remain as roots for these adult children and their families. This was indicated by the following statements:

- "I will as a parent figure not force anything on them, but tell them I will do this, but if you feel like doing it another way [which] will make you happy then follow your idea."

- "The second oldest daughter married into the Muslim religion, I said to her that this is her decision and she will be the one in the marriage."

- "They are adults and do not have to be accountable to me for their decisions."

One of the adult children said the following about her elderly parent:

- "We seem to get to the understanding that they know who I am as a person and who they are as a person."

- $\quad$ "So things are understood and respected more. He will say how he feels about something but never push his opinion on someone else."

An older parent continued to make a very bold statement in his view of parental dominance and the effects this has on the later stage of the parent-child relationship below:
- "You know a lot of parents I [can] think of inherently want a good relationship with their adult children, but allow it to deteriorate. Many times it is because of selfishness. They want their way and want to force their children to do what they feel they must do. One of my sisters in law is like that and [she] will tell her married daughter what she will or will not do. So parents have to let go. Children fly from the nest and will return. We need to welcome them back when they do."

- "I often think that in normal healthy families where relationships are not sound it is because of parental domination."

Literature advises older persons to think of their children as fellow adults and not as children (Arnett \& Mcmanus, 2011). In this way, adult children are regarded as individuals with their own ideas, feelings, opinions and way of doing things. Once parents treat their children as adults, they will react with maturity. This perspective is reiterated by an older parent in the research study:

- "The relationship with them is that of a peer relationship and once you realize that you treat them as peers you wouldn't try telling them what to do as much as you would not tell your best 60 year old friend or work colleagues how to run their lives."

Parenting according to Bettelheim (1987) is described as a process in which parents and children share their lives and grow together. Relationships are redefined as they grow together. People should not judge the current reality against the context of the past, but rather be more accepting of the way things are presently. Adult children can learn from both the flaws and strengths exhibited by their elderly parent . This was indicated by the following statement:

- $\quad$ "Not just him being the father all the time, but that both of us share in our joys and sorrows and learn from each other. As old as he is and as young as I am."

\section{Subtheme 2: The Lifespan of the Parent-child Relationship}

Responses from both adult children and older persons indicated that their relationships may have been partly due to the investment that parents made in their lives that would motivate them to assist their elderly parent when necessary and this would not just based on the fact that they feel obligated to. Therefore reciprocity seems to play a big role in whether or not adult children provide support to their ageing parents in later years. The results of Silverstein et al. (2002) research on the Investment Model of Reciprocity found that children who participated in more shared activities with their parents were more likely to reciprocate with activities in their parents' later years.

An adult child expresses their feeling of this below: 
- "I remember a specific school holiday and he was in the garage fixing a bicycle puncture and he said to me don't you wana [want to] go visit your friends. And I said no. I had lots of friends and still have lots of friends, but no I was quite happy just hanging around him in the garage."

- $\quad$ "He loves to be in his garden so I think as children we would go outside while he is pruning his trees and just be around him."

However other participants have indicated that this is not necessarily the case. They have responded that their relationships have not inherently always been good and they have had to make changes to the manner in which they relate to one another. This was indicated by the following statements:

- "No. It has not always been the case. I think when you grow up and you are younger you are a little bit more to yourself and you are not that sharing towards your parents, but I think when you grow a little bit older things make a little bit more sense to me as a person and am able to communicate more freely with them as they grow a little older and I grow older."

- "In the beginning it was like cultural that you not supposed to ask so many questions in our community. There seemed to be that pattern even when at times I think when they grew up they were not allowed to ask questions."

- "It changed when my dad, he has very good leadership qualities and the church noticed this. Society noticed this. Then he had to start to practice this in his family."

Even though some participants indicated that they have not always had good relationship in earlier years with their parents, Jacob et al. (2013) indicates that close relationships across the life span from the first stages of family development up until the later stages are viewed as continuations of these early attachment relations.

\section{Subtheme 3: Mutual Participation and Interaction by All Generations within the Family}

Throughout life, a give-and-take across all of the generations is a sign of family well-being. Older persons can continue to provide care for their children and grandchildren until they are no longer able. Middle-aged children receive love and aid from their parents and can also help their parents as needed. Grandchildren and children both contribute to and receive from the older generations.

Bengston (1997) found that mostly younger adult children have more integrated relationships with their parents than those in middle age. This is contradictory to the results of this research study because all adult children participants were middle aged and reflected having positive relationships with their parents. Bengston (1997) states this is unusual because younger adults generally require more assistance from parents when they are launching into adulthood. Once they are settled in careers with families of their own they are more likely to distance themselves from older parent-adult child relationship.

A very important aspect of relationships for older persons is that they ensure the environment for their adult children and even grandchildren is enjoyable and that they want to be around them. Older persons made sure that their adult children also experienced time spent with them as positive:

- "As a parent I feel that when my children are around me I must make them happy."

- "As a father I try my best to make my children happy."

All adult children in the study indicated they found a lot of pleasure and satisfaction spending time with the older person and enjoyed their company when they were together:

- "I believe it is the atmosphere that they provided us with. So it is enjoyable even if we go to the family we always go out together as a family. So I enjoy the time with them. They are very playful, they enjoyed jokes with us and participated even today. Today in a much more open way because they are older and I think their appreciation of us and that they want to be with us."

- "We enjoy each other's company but often we just sit next to each other in silence."

This mutual interaction in the lives of each other is extended beyond the parent-child relationship into the grandparent-grandchild relationship as well. Due to global increases in the life expectancy of people, it has become more likely for grandparents to have relationships with their grandchildren well into their early adulthood stages as indicated in the Family development theory (Duvall, 1962). This was indicated by the following statements:

- "We do everything together. We shop together, and she is here most weekends with our children. She is very involved in my child's upbringing... We go on holidays together and we spend a lot of time with each other. That is also a very unique if I think of some of my friends. Some of them do not want to spend that much time with parents. So the fact that we do spend so much time together and engage regularly is very positive."

- "We are very fond of our grandchildren when we come together our grandchildren are always keen to be around us. The love that we gave our children spilled over to our grandchildren."

Research undertaken by Öztop et al. (2009) found that when there is mutual support present between older persons and their adult children, there may be significant increase in life satisfaction for older persons.

\section{Subtheme 4: Communication}

Communication was a key element reflected throughout all of the interviews conducted in this research study, as the 
most vital aspect in elderly parent-adult child relationship. The ability of the adult child to tell the older person what bothers them in a very loving and respectful, yet assertive manner prevents resentment entering and disrupting the relationship.

This was reiterated in the study:

- "When we discuss something we come together as a family and put plans on the table and devise plans. This was one of the things I implemented in the family. That each and every one from the youngest to the oldest must be around the table and have a say or opinion in a safe place. We do not say yours is nonsense. Each opinion is listened to and together share what we think they could do. So every child in our home had a say. We did not with any one of the children tell [say] that they were unimportant. Each child had their own important role in our house."

Some researchers believe that communication within the parent-child relationship is vital in learning and understanding the feelings which each party experiences. When a child speaks to their parents they are learning how the parent will deal with their feelings and this in turn will build trust in the relationship. If a parent makes errors in their communication with their children, the child learns that their parents cannot be trusted with the information (Morin, 2014). Morin (2014) continues to say that there are often vital mistakes that parents make when communicating with their children. These are:

a) Minimizing their experiences/situation when they share whatever is going on in their lives.

b) Invalidating their children's feelings when at times they may be experiencing heightened emotions about things that seem irrelevant to the parent.

c) Making the conversation about oneself when one's child is disclosing difficulties and reminding them how difficult their parents may have had it when they were younger.

d) Passing immediate judgment and disapproval early in the conversation and isolating their child when they do not agree with them.

e) Showing shock at what their children are telling them.

f) Solving problems for their children even if it may be because they do not want them to experience pain.

g) Blaming and not being supportive of their children and their choices.

Within this study, older persons and their adult children referred very clearly to their experiences of communicating with each other in the relationship. The common mistakes made, were dealt with at an early stage in the relationship as indicated below:

- "We will sit around a table. They will explain to me what the situation is. Then if I feel I can give advice not because it must be like that but I will think of options for them to try if they want. If one of them phone[s] I will always think afterwards and send them a motivational religious message to help them get through what they are dealing with."

- "So we talk and get a solution to our problems."

- "So in terms of age difference there is a gap, but in terms of communication I can say that I can talk to both of them very openly."

\section{Subtheme 5: Respect}

Part of the evolution requires forging a new relationship, one between mature adults rather than between parent and child. The basic underpinnings of love and shared memories are already present. With mutual respect and common interests, a fulfilling relationship between parent and adult child can develop. This was confirmed by the participants:

- "That respect that we have for one another. Now whether you are the youngest or the oldest the respect remains the same. For me that is very important."

- "The respect for each other's space. I have always respected her space. I think that is important for children of parents who are growing older. Because you know what they may not want to sell their homes, sell their cars. Respect their choices and their space. Mutual respect."

\section{Summary of Research Findings}

\section{The Experiences of Older Persons and Adult Children of the Parent-child Relationship}

The study revealed that parents as well as their adult children derived great satisfaction from sharing positive relationships with each other. Both older persons as well as the adult children experienced their relationships to be satisfying. Older persons flagged support as being a rewarding and positive aspect of the relationship. Reciprocity was a dominant feature of the relationship where the older parent and the adult child received most satisfaction from the relationship when giving and receiving in the relationship was mutual and not one sided.

Adult children also felt that their experiences in these relationships were predominantly positive. This is contrary to what literature suggested, which stated that younger adult children who fall within the earlier stages of the Family Development Theory stages according to Duvall (1962) have more integrated relationships with their parents than those in middle age. This is contradictory to the results of this research study because all adult children participants were middle aged placing them in the later stages of the Family development (Duvall, 1962) ranging between stages six and seven and indicating strong positive relationships with their parents. Mutual reciprocity in the form of advice and caring for grandchildren was also received by the adult children from older persons; this indicated the interaction among the various systems taking place within these families which 
subscribes to the ecological systems theory. Thus ensuring balance is maintained and satisfaction of the relationships between older persons and their adult children.

\section{Significant Contributors to the Positive Older Person - Adult Children Relationship}

\section{Parental Non-dominance}

Parental non-dominance according to older persons and adult children had an overwhelming impact on the parent-child relationship in later life. It was very evident that both the parents and their adult children felt that parents should readjust and take on different roles when the adult children become more independent and start families of their own. Interestingly enough the significance of parental non-dominance came through very strongly from older persons feeling that parents need to remember what it is like to be an adult child. Older persons also needed to realize that their children no longer required the same involvement they needed when they were younger. Older persons felt that their children no longer needed to ask permission and should not be made to feel guilty if they did things that their parents did not agree with. Once this is realized, the relationship is experienced at a completely different level and satisfaction of both older persons and their adult children in the relationship increases tremendously.

\section{The Lifespan of the Parent-child Relationship}

This subtheme covered how the lifespan of the parent-child relationship changes and evolves over time. It was evident that older persons-adult child relationships went through various stages, with the participants accommodating each other and thereby creating relationships perceived as positive. It is important to recognize that all relationships fluctuate and grow continuously throughout life. The lifespan of the parent-child relationship indicates that it is not always necessary for the parent-child relationship to be considered as positive and that many challenges will be experienced over time during the relationship. However irrespective of these challenges, the relationships experienced by older persons and their adult children in this study were still inherently perceived as satisfying.

\section{Mutual Participation and Interaction by All Generations within the Family}

Time spent together and having mutual interaction across generations was indicated by both older persons and adult children as important to their relationships. When one party is not able to provide, then it comes from the other and vice versa. This does not necessarily only mean finances, but interest in activities that grandchildren are involved in or initiating contact from both sides. Older persons also indicated the importance of making the visits enjoyable in order to ensure that time spent together is not forced or because of obligation, but because they want to spend time together and enjoy each other's company.

\section{Respect}

Mutual respect between older persons and their adult children was imperative in developing and maintaining a positive relationship that remained stable over long periods of time. When older persons and adult children treated each other with respect, the manner in which they dealt with situations was different than when they did not have respect for one another.

\section{Conclusions and Recommendations}

Based on the findings of the research study, the following conclusions and recommendations were arrived at:

\section{Practice}

- Micro level: Social workers working in social gerontology are often faced with older persons who have very strained relationships with their adult children. Both these systems need to interact in positive ways in order for balance and homeostasis to be achieved in the relationship (Bronfenbrenner, 1994). If there are poor relationships there is much distress for both parties. Professionals in the field need to assist families in alleviating the negative effects of these relationships by informing these families of the findings of this study. When working in a therapeutic manner with older persons and adult children it would be beneficial for the practitioner to explore with the clients the experiences expressed by participants such as their parental non dominance in the relationship, as well as how the lifespan of their relationship may have impacted the quality. Therapeutic sessions could be more focused and directed nurturing understanding in the relationship which interacts with various systems around them and do not function in isolation. Professionals should realize the importance of the parent-child relationship in later years and the impact it has on older persons' parent, the adult child and the larger systems in which these relationships function. Effective services provided to older persons and their adult children early on could provide relief from pressure placed on government and other formal sectors in the community for the care and support of older persons, as these relationships require assistance from professionals in social gerontology.

- Mezo level: Support groups and older person-adult child workshops aimed at those who are struggling in their relationships in order to improve these vital relationships. In this context they can share experiences of their intergenerational relationships, initiated by social workers and related professionals 
to cultivate an atmosphere for restoring and/or resurrecting relationships.

- Macro level: Society needs to understand the importance of the older generations in our communities. There needs to be better integration of older persons into activities in the communities instead of moving them out and into isolation. Keeping older persons active is vital to their quality of life. Initiating programs in schools where older persons become part of the daily lives of children imparting knowledge and skills to younger generations. This allows for the older person who is in the last stages of family development to have a sense of worth. Many institutions lack resources and this link could assist the organisations, older persons and the younger generations involved by cultivating a culture of respect for older persons. This also allows for older persons to remain connected to the systems in their environment possibly delaying onset of increased assistance from adult children and also allowing for the larger systems in the environment to accommodate and utilize increased time that the older person has available instead of this time becoming the burden on the adult child to fill.

\section{Policies}

- More collaboration is needed between the various stakeholders involved in the care of older persons in the community. It is evident in South Africa that the policies and legislation that is drawn up in order to various vulnerable populations in society are well formulated; however, the concern comes in with implementation of these policies. The Older Persons Act (RSA, 2006), as discussed in the study promotes the independence and interaction of older persons with systems around them during this last stage of family development, however the structures in the community do not always support these policies. These structures and institutions should be developed to assist older persons to remain independent and to enjoy their families, instead of being dependent on them for support. It is imperative that all stakeholders contribute towards developing policies that are practical and able to be implemented in South Africa for this to be possible. In this study it became evident that the community consists of larger groups of aged people. Both formal and informal support systems need to collaborate to assist with positive development among the older generation.

- Resources, such as funding and facilities for those professionals who are working in the field of social gerontology should be made available. This will facilitate processes for effective intervention strategies to increase the resilience of and contribute to positive relationships between older persons and their adult children.

\section{Training}

Older persons are a unique population that training has been overlooked for. Universities could include more training in their curriculum on working with older persons as they are clearly becoming more relevant than in previous years with increased life span and the roles that older persons have in the systems around them. Professionals need to ensure that they stay abreast of the new developments in the field of older persons as this is a rapidly expanding field by taking continuing professional development courses on gerontology. More training should be made available for professionals working in with older persons to improve the relationship with adult children.

\section{Theory}

The ecological systems theory as well as the family development theory was utilized for this study to emphasise the importance of viewing the older person as well as the adult child in context of their environment and at different places in life. Professionals could also assist the older persons understand that based on their expectations of their own beliefs, values of what adult children should be doing can be different to what the view is of their adult child based on the ecological systems theory these dimensions explored could assist the relationship in healing. Social workers should understand the integration of these theories into practice and be able to assess the imbalances that are present in the relationships of older persons and their adult children and use the knowledge of these theories to assist in achieving the homeostasis between the environment of the older person and the adult child.

\section{Future Research}

Further research can explore in more detail, positive intergenerational relationships and the impact that they have on the participants. In addition, the valuable contribution older persons impart on these relationships that are often forgotten about by society can be investigated.

\section{Concluding Remarks}

This study aimed to gather the experiences of older persons and their adult children of their positive and satisfying relationship with one another. This was accomplished by listening to the stories of both older persons and their adult children with whom they felt they had a positive relationship. By exploring these narratives, it became evident that even though they experienced their relationships as positive there were definitely challenges present over their life span. This indicates that even in the 
presence of challenges, these relationships can be fulfilling and still be a great source of support for both older persons and their adult children. In these relationships it also became apparent that the adult children who participated did not offer support to the older person out of obligation as previous research suggests, but out of respect and love for the older person.

In a South African as well as a global context, limited knowledge is available and little research has been conducted in terms of what make these relationships work. There is an abundance of research available on negative aspects of the relationship between older persons and their adult children and why they are 'forgotten'. Therefore this study is important as it contributes to our understanding of relationship strengths and emphasizes the positive aspects of these relationships. Various factors may impact differently on families, however in this study it became evident among people of different statuses, socio-economic levels and even race groups that the findings which emerged all had a similar thread. In these strengths, it is important to acknowledge and not dismiss the findings of what does contribute to the knowledge base of social gerontology.

\section{REFERENCES}

Abeles, R. P., Gift, H. \& Ory, M. (1994). Aging and quality of life. New York: Springer Company.

Bettelheim, B. (1987). A good enough parent. New York: Knopf.

Birditt, K. S., Miller, L. M., Fingerman, K. L. \& Lefkowitz, E. S. (2009). Tensions in the parent and adult child relationship: Links to solidarity and ambivalence. Psychology and aging. Vol 24. pp 287-295.

Bloomberg, L. \& Volpe, M. (2012). Completing your qualitative dissertation. A road map from beginning to end (2nd ed.). United States: Sage Publications.

Bookman, A. \& Kimbrel, D. (2011). Families and elder care in the twenty first century. Pubmed Gov.

Bronfenbrenner, U. (1994). International encyclopedia of education Vol 3, (2nd ed.). Oxford: Elsevier.

Creswell, J. W. (2013). Qualitative inquiry and research design. Choosing among five approaches (3rd ed.). United States: Sage Publications.

DE Vos, A. S. (2005). Research at grass roots for the social sciences and human services professions. Pretoria, Van Schaik

Duvall, E. M. (1962). Family development (2nd ed.). Philadelphia: Lippincott.

Erikson, E. (1983). Childhood and society (2nd ed.). New York: Norton.

Erikson, E. H., Paul, I. H., Heider, F., \& Gardner, R. W. (1959). Psychological issues Vol. 1. International Universities Press.

Ferring, D., Michels, T. \& Boll, T. (2009). Emotional relationship quality of adult children with ageing parents: On solidarity, conflict and ambivalence. European Journal of aging. Vol. 6 (4), pp. 253-265.

Frankl, V. (1997). Man's search for ultimate meaning. New York: Perseus Publishing.

Gelineau, K. (June 9, 2013). Global study: World not ready for aging population. Retrieved 17 September 2013 from www.bigstory.ap.org/article/global-study-world-not-ready-for-agi ng-population.

Global Age Watch Report (2013). Insight report. Institution of development studies. Sussex: University of Sussex.

Henry, C. S., Plunkett, S. W. \& Sands, T. (2011). Family structure, parental involvement and academic motivation in Latino adolescents. Journal of Divorce and Remarriage, 52 (6), 370-390.

Jacob, L., Gewirtz, W., Kurtines, J. \& Lamb, L. (2013). Handbook of moral behaviour and development. New York and London: Psychology Press.

Kinsella, K. (2005). Population bullentin. Global aging: The challenge of success, Population Reference Bereau, 60 (1), pp.5-38.

Lowenstein, A., Katz, R. \& Gur-Yaish, N. (2007). Reciprocity in parent-child exchange and life satisfaction among older persons : A cross national perspective. Journal of Social Issues, 63 (4), $865-883$

Morin, A., (2014). 10 Communication mistakes parents make that discourage teens from talking. Retrieved 17 September 2015 from http://parentingteens.about.com/od/talktoyourteen/fl/10-Communi cation-Mistakes-that-Discourage-Teens-from-Talking.htm.

National Institute on Ageing. (2011). Why population ageing matters. Global perspective. Retrieved from http:// HYPERLINK "http://www.nia.nih.gov" www.nia.nih.gov

Newby, K. (2010). After you say "I do": Adjusting to marriage. Journal of Family and consumer sciences. Ohio State University. Retrieved 6 June 2013 from ohioline.osu.edu/flm01/pdf/fs02.pdf.

O'Connor, P. (1994). Very close parent/child relationships. The perspective of older persons person. Journal of Cross-Cultural Gerontology, 9, 53-76.

Pickhardt, C. E. (June 22, 2010). Surviving (your child's) adolescence. Retrieved 17 June 2015 from

file://E:/Parenting\%20After\%20the\%20Adolescent $\% 20$ Becomes \%20Adult\%20_\%20Psychology\%20Today.html

Powell, A. (2013). Mandela's Care Spotlights S. Africa Healthcare Needs for Older persons Retrieved 09 August 2014 from http://www.voanews.com/content/mandela-care-spotlights-south-a frica-healthcare-for-older persons /1685957.html

Ramshala, M. (2000). Living arrangements, poverty and health of older persons in Africa. Psychology and Aging, 24 (2), 287-295.

Rosenberg-Jarvors, I., (2006). Aging Alone? Retrieved 25 July 2014 from americanpsychotherapy.com

Rossman, G. \& Rallis, S. (2012). Learning in the field: An introduction to qualitative research (3rd ed.). Massachusetts: Sage Publications.

Silverstein, M., Conroy, S., Wang, H., Giarrusso, R. \& Bengston, 
V. (2002). Reciprocity in parent-child relations over the adult life course. Journal of Gerontology: Social Sciences. Vol. 57B (2). pp.S3-S13.

Swain, J. (June 15, 2011). Letting go: When alienated parents give up. Retrieved 03 September 2013 from

2011/11/20/letting-go-when-alienated-parents-give-up/

White Paper on Families in South Africa. (2012). Republic of
South Africa: Department of Social Development.

WHO. (2011). World Health Organisation. Retrieved September 15, 2013 from www.who.int/ageing/en/2014

Wurtzel, N. (2014). Can society force adult children to visit elderly? Retrieved from

http://www.vibrantnation.com/family-relationships/can-society-for ce-adult-children-to-visit-their-elderly -parents/ 